CLINICAL STUDY

\title{
Adiponectin is associated with low bone mineral density in elderly men
}

\author{
Lourdes Basurto $^{1}$, Rosa Galván ${ }^{1}$, Nydia Cordova ${ }^{1}$, Renata Saucedo ${ }^{1}$, Columba Vargas ${ }^{2}$, Sandra Campos ${ }^{1}$, \\ Elizabeth Halley ${ }^{2}$, Francisco Avelar ${ }^{2}$ and Arturo Zárate ${ }^{1}$ \\ ${ }^{1}$ Endocrine Research Unit and ${ }^{2}$ Department of Radiology, National Medical Center, Instituto Mexicano del Seguro Social, Cuauhtémoc 06720 Mexico \\ (Correspondence should be addressed to L Basurto; Email: lbasurtoa@yahoo.com)
}

\begin{abstract}
Objective: Recent evidence suggests that adiponectin may play a role in bone metabolism. Previous studies demonstrated that the adiponectin levels had a negative correlation with bone mineral density (BMD) in women. However, little is known about the relationship between adiponectin and BMD in men. The aim of this study was to determinate the relationship between the adiponectin levels and BMD in elderly men.

Design: Cross-sectional study including 92 healthy men aged 60-80 years.

Methods: Main outcome measures were the adiponectin levels estimated by RIA and BMD at lumbar spine and femoral neck using dual energy X-ray absorptiometry.

Results: The negative correlation between adiponectin and BMD at the spine was $r=-0.209$, $(P<0.05)$ and at the femoral neck was $r=-0.237,(P<0.001)$. These correlations disappeared after adjustment for body mass index (BMI). When stratified by BMI, the relationship between BMD and adiponectin remained significant in the subgroup of participants with BMI $>27 \mathrm{~kg} / \mathrm{m}^{2}$, but disappeared in men with BMI $\leq 27 \mathrm{~kg} / \mathrm{m}^{2}$. In multiple regression analysis, adiponectin was a significant determinant of BMD at the spine, not at the femoral neck, in those with BMI $>27$.

Conclusion: BMD is negatively associated with the adiponectin levels in men older than 60 years and this relationship is greater in those men with BMI $>27$, which suggests a plausible connection between bone and fat tissue.
\end{abstract}

European Journal of Endocrinology 160 289-293

\section{Introduction}

There are many reports indicating that osteoporosis and particularly hip fractures are less common in obese individuals $(1,2)$. Body weight has generally been considered as a predictor of bone mineral density (BMD) for both males and females $(3,4)$. Although mechanical load forces may contribute to this relationship, other factors such as sexual hormones, glucocorticoids, and insulin are also involved (5-7). It has been recently suggested that the association of BMD with body weight might also be mediated by hormonal factors secreted by adipocytes, including leptin and adiponectin (8-11).

Adiponectin is one of the most abundant circulating proteins and it is the only adipocytokine known to date, which is negatively regulated in obesity (12). In particular, adiponectin seems to act in bone metabolism, inducing osteoblast differentiation and increasing osteoclast formation, through the stimulation of the receptor activator of nuclear factor- $\mathrm{KB}$ (RANK) pathway. This pathway, in turn, plays a role in the development of osteoporosis (13-15). The clinical association between the serum adiponectin level and BMD has been studied by several groups. In a study on adolescent women, a negative correlation was found between the adiponectin levels and BMD, which was not apparent after adjustment for fat mass (16). Richards et al. (17) found a similar association in postmenopausal women, which remained significant after adjustment for body mass index (BMI). This observation was consistent in premenopausal women $(9,18)$. Nevertheless, little is known about the association between the adiponectin levels and BMD in men.

We tested the hypothesis that the adiponectin levels could be negatively associated with BMD. Thus, the aim of the present study was to determine the relationship between the adiponectin levels and BMD in men older than 60 years.

\section{Subjects and methods}

This was a cross-sectional and single-center study. Ninety-two healthy men over 60 years of age were included in this study, and they were recruited from March 2004 through January 2005. The subjects were recruited by asking female participants of other studies conducted by the Endocrine Research Unit whether 
they knew any man who might be interested in volunteering for the study.

Participants were interviewed for medical history and underwent a complete physical examination. Subjects with a history of diabetes, renal failure, chronic infections, malignancy, metabolic bone diseases, hypertension, history of recent cardiovascular disease, gastrointestinal or liver disease, active smoking, obesity secondary to endocrine disease, hematological abnormalities, and participation in any strenuous physical exercise were excluded from the study. Moreover, the subjects who received any medications affecting bone metabolism (vitamin D, calcium, calcitonin, bisphosphonates, or glucocorticoid) or more than $30 \mathrm{ml}$ of alcoholic drinks per day were also excluded.

Body weight and height of the participants were measured without shoes, with light clothing, by using a Bame scale to a precision of $0.5 \mathrm{~kg}$ and a Bame stadiometer to a precision of $0.5 \mathrm{~cm}$. BMI was calculated as the weight (in $\mathrm{kg}$ ) divided by the square of the height (in $\mathrm{m}^{2}$ ). For analysis, two categories of BMI were defined: less than $27 \mathrm{~kg} / \mathrm{m}^{2}$, and $27.1 \mathrm{~kg} / \mathrm{m}^{2}$ or more $(19,20)$.

The study was approved by the ethics committee of the Instituto Mexicano del Seguro Social. The volunteers were informed about the trial, and a written consent was signed by all of them.

\section{Hormone analysis}

Fasting blood samples were obtained from an antecubital vein between 0730 and $0830 \mathrm{~h}$ using vacuum tubes with EDTA anticoagulant; these samples were promptly centrifuged at $400 \mathrm{~g}$ for $15 \mathrm{~min}$. The plasma samples were aliquotted and stored at $-70{ }^{\circ} \mathrm{C}$ until they were assayed in a single run hormone assay. The adiponectin levels were measured by a specific RIA using commercial kits from Linco Research, St Charles, MO, USA. The intra- and interassay coefficients of variation $(\mathrm{CV})$ were 3.9 and $8.5 \%$ respectively. Knowing that the adiponectin levels are in $\mu \mathrm{g} / \mathrm{ml}$ concentrations, samples were diluted to $1 / 500$ in assay buffer before estimation. The analytical sensitivity of this assay was $0.05 \mu \mathrm{g} / \mathrm{ml}$, as reported previously (21).

\section{Bone mineral density}

BMD was measured at the lumbar spine (L1-L4 together) and the hip (femoral neck) by dual energy X-ray absorptiometry using a Lunar distrene-plasticizerxylene densitometer scanner (GE Lunar Corporation, Madison, WI, USA). Scanning was performed according to the instructions of the manufacturer; the $\mathrm{CV}$ for this technique was $1.0 \%$ in the lumbar spine and $1.3 \%$ in the hip. Calibration was performed routinely every morning using the standard provided by the manufacturer. All subjects were tested on the same machine and by the same operator.

\section{Statistical analysis}

The Kolmogorov-Smirnov statistical test was used to test the normality of the distributions and a parametric statistical analysis was done. The data are expressed as means \pm s.D. Correlation analyses between the adiponectin and anthropometric data and BMD were performed with Pearson's correlation test and partial correlation analyses were performed to adjust for age and BMI. Regression analyses models were used to test the relationship of $\mathrm{BMD}$, with adiponectin, age, and BMI. Comparisons resulting in $P=0.05$ were considered statistically significant. All statistical analyses were performed using the computer program statistical software SPSS version 12.0.

\section{Results}

Characteristics of the participants with the age ranging between 60 and 80 years are shown in Table 1 . Of the total of 92 participants, $50(54.3 \%)$ had BMI $\leq 27 \mathrm{~kg} / \mathrm{m}^{2}$ and $42(45.7 \%)$ had BMI $>27 \mathrm{~kg} / \mathrm{m}^{2}$. The adiponectin level of participants with overweight/ obesity was reduced in comparison with participants with normal body weight $(8.17 \pm 3.33$ vs $9.7 \pm$ $5.59 \mu \mathrm{g} / \mathrm{ml}, P<0.05)$.

The Pearson correlation coefficient between the adiponectin levels and age was $r=0.271(P<0.001)$, and between adiponectin and BMI was $r=-0.130$ $(P<0.05)$. Moreover, adiponectin was correlated with body weight $(r=-0.228, P=0.02)$. Table 2 shows the association between adiponectin and BMD. Adiponectin values were negatively correlated with both lumbar BMD $(r=-0.209, \quad P<0.05)$ and femoral BMD $(r=-0.237, P<0.001)$. Such correlations remained significant after adjustment for age, but were not present after adjustment for BMI.

Multivariate regression models were applied to explore the relationship between adiponectin and BMD. The dependent variables were BMD at lumbar spine and femoral neck. Several independent variables such as age, BMI, and adiponectin levels were included in the regression models. When femoral neck BMD was considered as the dependent variable in a multiple regression analysis, BMI, but not the adiponectin, was

Table 1 General characteristics of participants.

\begin{tabular}{lc}
\hline & $\boldsymbol{n}=\mathbf{9 2}$ \\
\hline Age (years) & $64.3 \pm 7.7$ \\
Body mass index $\left(\mathrm{kg} / \mathrm{m}^{2}\right)$ & $27.6 \pm 3.4$ \\
Body weight $(\mathrm{kg})$ & $74.0 \pm 8.4$ \\
Body height $(\mathrm{m})$ & $1.64 \pm 0.07$ \\
Adiponectin $(\mu \mathrm{g} / \mathrm{ml})$ & $9.28 \pm 4.86$ \\
Lumbar density $\left(\mathrm{g} / \mathrm{cm}^{2}\right)$ & $1.111 \pm 0.173$ \\
Femoral density $\left(\mathrm{g} / \mathrm{cm}^{2}\right)$ & $0.931 \pm 0.176$
\end{tabular}

Data are expressed as the mean ( \pm s.D. $)$ 
Table 2 Correlations between the adiponectin levels and bone mineral density (BMD).

\begin{tabular}{llll}
\hline & \multicolumn{3}{c}{ Adiponectin } \\
\cline { 2 - 4 } & Unadjusted & $\begin{array}{c}\text { Adjusted } \\
\text { for age }\end{array}$ & $\begin{array}{c}\text { Adjusted } \\
\text { for BMI }\end{array}$ \\
\hline BMD & & & \\
Spine (L1-L4) & $-0.209^{*}$ & $-0.155^{*}$ & -0.126 \\
Femoral & $-0.237^{\dagger}$ & $-0.195^{\star}$ & -0.093 \\
\hline
\end{tabular}

${ }^{*} P<0.05,{ }^{\dagger} P<0.001$.

the independent predictor of BMD. No significant relationships were observed with spine BMD (Table 3).

When the analysis was done by considering the BMI, the subgroup of participants with BMI $>27.1$ showed that adiponectin had a negative correlation with lumbar spine BMD $(r=-0.456, P=0.002)$ and femoral BMD $(r=-0.162, P<0.05)$. The above correlations remained significant after the adjustment for BMI. In this subgroup of men, multiple linear regression analysis, with BMD as the dependent variable and BMI, age, and adiponectin as independent variables, was also done. The analysis suggests that the lumbar BMD maintain an independent relationship with adiponectin (Table 3). By contrast, there was no significant correlation between adiponectin and BMD in another subgroup of men having $\mathrm{BMI} \leq 27$.

\section{Discussion}

The direct association existing between body weight and the reduction of fractures has been shown in various studies $(2,22-24)$. Although there are several factors, such as mechanical loading forces, aromatization of testosterone in adipose tissue, and insulin concentrations, which may contribute to the relationship between body weight and BMD recently it has been shown that some adipocytokines secreted by adipose tissue play a role in bone metabolism (6-8). Adiponectin is one of the hormones that support the link between adipose and bone tissue (12). It has been observed that the serum concentrations of this hormone correlate negatively with BMD in the female population $(9,15$, 17,18 ); however, there are only limited number of studies conducted to determine this relationship in men $(25,26)$.

The present study showed an inverse association between the adiponectin concentrations and the bone density in men older than 60 years. These findings agree with the study by Peng et al. which was conducted on a population of a very wide age range (20-80 years) and, therefore, with significant BMD variations (25). On the contrary, in another study on males (26), no association was found between adiponectin and BMD; however, the small sample size, lack of adjustment in

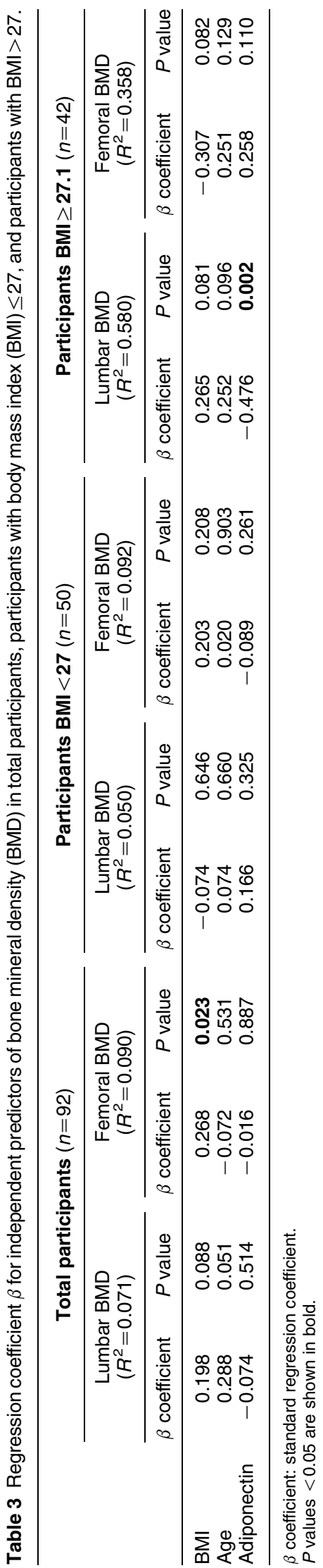

www.eje-online.org 
some confounding variables (alcoholism and tobacco addiction), and the participants' wide age range could have affected the results of this study (27-29). By contrast, for the present study it was agreed to choose men older than 60 years of age, since this is the stage of life in which demineralization problems become apparent.

Although the results of some studies have been contradictory, the possible relationship between adiponectin and BMD is supported by the evidence, such as the identification of adiponectin receptors in both osteoblasts and osteoclasts (30), and the proof that adiponectin increases osteoclastogenesis indirectly by stimulating RANKL and by inhibiting the production of osteoprotegerin in human osteoblasts $(31,32)$.

The results of the present study demonstrated a strong relationship between the adiponectin levels and BMD in participants who presented greater BMI. Moreover, a multiple regression analysis indicated that adiponectin is an independent predictor of BMD in this subgroup of men. Conversely, these associations were not observed in patients with BMI $\leq 27$. To this respect, other factors like altered levels of estrogens, insulin, and other adipokines in obesity, modifying the relationship between adiponectin and bone, could be explain the differences $(17,33)$.

This study has some limitations. Since it was not designed for stratified analysis, it is required that the studies directed towards evaluating the possible differences between participants with normal weight and overweight should be conducted. Another consideration of this study is that BMI was used only to measure body fat, although there are other precise methods like DXA scan. The BMI does not quantify total body adiposity, but is correlated with body fatness and is a method accepted to measure obesity $(34,35)$. Furthermore, even though this study was cross-sectional and therefore inferences of causality cannot be established, the results may suggest that adiponectin might play a role in the bone balance, particularly in elderly men with overweight. On the other hand, it can be pointed out that the influence of potential confounders was reduced by limiting the age, heavy physical activity, tobacco addiction, and alcoholism in the inclusion criteria of the present study.

In conclusion, this study demonstrated that men older than 60 years of age exhibit an inverse relationship between the adiponectin levels and BMD, particularly when BMI is above normal limits. However, no definitive conclusions can be obtained; the study data support that adiponectin is involved in the interrelationship between adipose tissue and bone.

\section{Declaration of interest}

The authors declare that there is no conflict of interest that would prejudice the impartiality of this paper.

\section{Funding}

This work was supported in part by a grant FOFOI 2006/1A1/056 from the Mexican Institute of Social Security (IMSS).

\section{Acknowledgements}

We thank Elizabeth Garcia and Sara Vega for their technical assistance.

\section{References}

1 Albala C, Yanez M, Deveto E, Sostin C, Zeballos L \& Santos JL. Obesity as a protective factor for postmenopausal osteoporosis. International Journal of Obesity and Related Metabolic Disorders 1996 20 1027-1032.

2 Van der Woort DJ, Geusens PP \& Dinant GJ. Risk factors for osteoporosis related to their outcome: fractures. Osteoporosis International 200112 630-638.

3 Kichengast S, Peterson B, Hauser G \& Knogler W. Body composition characteristic is associated with the bone density of proximal femur in middle and old-aged women and men. Maturitas 200139 133-145.

4 Felson DT, Zhang Y, Hannan MT \& Anderson JJ. Effects of weight and body mass index on bone mineral density in men and women: the Framingham study. Journal of Bone and Mineral Research 1993 8 567-573.

5 Zhao LJ, Liu YJ, Liu PY, Hamilton J, Recker RR \& Deng HW. Relationship of obesity with osteoporosis. Journal of Clinical Endocrinology and Metabolism 200792 1640-1646.

6 Perusse L, Rankinen T, Zuberi A, Chagnon Y, Weisnagel S, Argyropoulos G, Walts B, Snyder E \& Bouchard C. The human obesity gene map: the 2004 update. Obesity Research 200513 381-490.

7 Gimble J, Zvonic S, Floyd Z, Kassem M \& Nuttall M. Playing with bone and fat. Journal of Cellular Biochemistry 200698 251-266.

8 Zoico E, Zamboni M, Adami S, Vettor R, Mazzali G, Tosoni P, Bissoli L \& Bosello O. Relationship between leptin levels and mineral density in the elderly. Clinical Endocrinology 200359 97-103.

9 Jürimäe J \& Jürimäe T. Adiponectin is a predictor of bone mineral density in middle-aged premenopausal women. Osteoporosis International 200718 1253-1259.

10 Jürimäe J \& Jürimäe T. Influence of insulin-like growth factor -1 and leptin on bone mineral content in healthy premenopausal women. Experimental Biology and Medicine 2006231 1673-1677.

11 Roux C, Arabi A, Porcher R \& Garnero P. Serum leptin as a determinant of bone resorption in healthy postmenopausal women. Bone 200333 847-852.

12 Lenchik L, Register T, Hsu F, Lohman K, Nicklas B, Freedman B, Langefeld C, Carr J \& Bowden D. Adiponectin as a novel determinant of bone mineral density and visceral fat. Bone 2003 4 646-651.

13 Bell N. RANK ligand and the regulation of skeletal remodeling. Journal of Clinical Investigation 2003111 1120-1122.

14 Yokota T, Meka C, Medina K, Igarashi H, Comp P \& Takahashi M. Paracrine regulation of fat cell formation in bone marrow cultures via adiponectin and prostaglandins. Journal of Clinical Investigation 2002109 1303-1310.

15 Jürimäe J, Rembel K, Jürimäe T \& Rehand M. Adiponectin is associated with bone mineral density in perimenopausal women. Hormone and Metabolic Research 200537 297-302.

16 Huang KC, Cheng WC, Yen RF, Tsai KS, Tai T-Y \& Yang W. Lack of independent relationship between plasma adiponectin, leptin levels and bone density in nondiabetic female adolescents. Clinical Endocrinology $200461204-208$. 
17 Richards JB, Valdes AM, Burling K, Perks UC \& Spector TD. Serum adiponectin and bone mineral density in women. Journal of Clinical Endocrinology and Metabolism 200792 1517-1523.

18 Jürimäe J \& Jürimäe T. Plasma adiponectin concentration in healthy pre- and postmenopausal women: relationship with body composition, bone mineral, and metabolic variables. American Journal of Physiology. Endocrinology and Metabolism 2007293 E42-E47.

19 Sanchez-Castillo CP, Velázquez-Monroy O, Berber A, LaraEsqueda A, Tapia-Conyer R \& James WP. Encuesta Nacional de Salud (ENSA) 2000 Working Group. Anthropometric cutoff points for predicting chronic diseases in the Mexican National Health Survey 2000. Obesity Research $200311442-451$.

20 Berber A, Gomez-Santos R, Fanghanel G \& Sanchez-Reyes L. Anthropometric indexes in the prediction of type 2 diabetes mellitus, hypertension and dyslipidaemia in a Mexican population. International Journal of Obesity and Related Metabolic Disorders 2001 25 1794-1799.

21 Galvan RE, Basurto L, Saucedo R, Campos S, Hernandez M \& Zárate A. Adiponectin concentrations during menstrual cycle. Ginecología y Obstetricia de México 200775 435-438.

22 Edelstein SL \& Barrett-Connor E. Relation between body size and bone mineral density in elderly men and women. American Journal of Epidemiology 1993138 160-169.

23 Ribot C, Tremollieres F, Pouilles JM, Bonneu M, Germain F \& Louvet JP. Obesity and postmenopausal bone loss: the influence of obesity on vertebral density and bone turnover in postmenopausal women. Bone 19878 327-331.

24 Tremoilleres FA, Pouillet JM \& Ribot C. Vertebral postmenopausal bone loss is reduced in overwheight women a longitudinal study in 155 early postmenopausical women. Journal of Clinical Endocrinology and Metabolism 199377 683-686.

25 Peng X, Xie H, Zhao Q, Wu X, Sun Z \& Liao E. Relationships between serum adiponectin, leptin, resistin, visfatin levels and bone mineral density, and bone biochemical markers in Chinese men. Clinica Chimica Acta 2008387 31-35.

26 OH K, Lee W, Rhee E, Baek K, Yoon K, Kang M, Yun E, Park C, Ihm S, Choi M, Yoo H \& Park S. The relationship between serum resistin, leptin, adiponectin, ghrelin levels and bone mineral density in middle-aged men. Clinical Endocrinology 200563 $131-138$
27 Bendavid E, Shan J \& Barret-Connor E. Factors associated with bone mineral density in middle-aged men. Journal of Bone and Mineral Research 199611 1185-1190.

28 Hannan M, Felson D, Dawson-Hughes B, Tucker K, Cupples L, Wilson P \& Kiel D. Risk factors for longitudinal bone loss in elderly men women: the Framingham Osteoporosis Study. Journal of Bone and Mineral Research 200015 710-720.

29 May H, Murphy S \& Khaw K. Alcohol consumption and bone mineral density in older men. Gerontology 199541 152-158.

30 Berner HS, Lyngstadaas SL, Spahr S, Monjo M, Thommesen L, Drevon CA, Syversen U \& Reseland JE. Adiponectin and its receptors are expressed in bone-forming cells. Bone 200435 842-849.

31 Luo XH, Guo IJ, Xie H, Yuan LQ, Zhou HD \& Liao EY. Adiponectin stimulates RANKL and inhibits OPG expression in human osteoblasts through the MAPK signaling pathway. Journal of Bone and Mineral Research 200621 1648-1656.

32 Shinoda Y, Yamaguchi M, Ogata N, Akune T, Kubota N, Yamauchi T, Terauchi Y, Kadowaki T, Takeuchi Y, Fukumoto S, Ikeda T, Hoshi K, Chung UI, Nakamura K \& Kawaguchi H. Regulation of bone formation by adiponectin through autocrine/ paracrine and endocrine pathways. Journal of Cellular Biochemistry 200699 196-208.

33 Engeli S, Feldpausch M, Gorzelniak K, Hartwig F, Heintze U, Janke J, Möhlig M, Pfeiffer AFH, Luft FC \& Sharma AM. Association between adiponectin and mediators of inflammation in obese women. Diabetes 200352 942-947.

34 Deurenberg P, Andreoli A, Borg P, Kukkonen-Harjula K, deLorenzo A, van Marken Lichtenbelt WD, Testolin G, Vigano R \& Vollaard N. The validity of predicted body fat percentage from body mass index and from impedance in samples of five European populations. European Journal of Clinical Nutrition 200155 973-979.

35 Kuczmarski RJ \& Flegal KM. Criteria for definition of overweight in transition: background and recommendations for the United States. American Journal of Clinical Nutrition 200072 1074-1081.

Received 10 November 2008

Accepted 13 November 2008 